\title{
Encountering the "Politics of Fear": Teacher Training for a Media Propaganda Education to Prevent Political Extremism, In the Context of DEMOKLEOS, Erasmus+ KA2- Project
}

\author{
Dr. Constantina Spiliotopoulou
}

\begin{abstract}
:
Under the weight of the "Politics of fear" pervading contemporary life, teachers are obliged to work in a difficult climate dominated by ideas and practices which directly affect human rights and democracy. Recruitment of young people by violent extremist networks throughout Western countries is constantly increasing. Along with this increase has come a constructive discussion about teachers' training and programs that empower participants to respond to Media extremist Propaganda. Emphasis on prevention is the key. Despite the fact that online environments are now central to Political Propaganda, Media Political Education in schools is virtually non-existent. In the vast majority of EU Member States, there is no provision of formal teacher training in Media Literacy or Media Propaganda Education. The overall aim of the Erasmus+, KA2 project DEMOKLEOS The KLEOS of Democracy in European School, Rethinking Democratic Awareness and Collective Responsibility for a Whole Approach is to provide educators with the necessary tools, mainly through open training activities, aimed at facilitating the identification on-line of 'political extremist' motivated hate communication. A communication-based training concept has been worked out, for teachers of the Secondary Education and for their school students. Specific forms of Political Literacy education had been elaborated, which provide skills to analyse the media, but also enable critical idealism to be fostered. Moreover, one of the specific objectives of the project was to raise Democratic Awareness on issues such as political propaganda, indoctrination and fake news found in the online environment and the influence of social media on politics and civil society.
\end{abstract}

Keywords: Teacher training, Media Propaganda Education, Political Extremism, Political literacy, Erasmus+ DEMOKLEOS 


\section{International Academic Conference on Teaching, Learning and Education}

MILAN, ITALY

\section{European teachers under the weight of the "Politics of fear"}

Under the weight of the "Politics of fear" 1 pervading contemporary life, teachers are obliged to work in a difficult climate dominated by ideas and practices which directly affect human rights and democracy. As a start point of our discussion, we could quote Altheide (2006, p. 424), "The politics of fear serves as a conceptual linkage for power, propaganda, news and popular culture, and a ray of intimidating symbols and experiences, such as crime and terrorism". It is no news to point out that the amazing successes of many of the anti-immigrant and nationalistic political groupings in Europe are based on manufacturing a politics of fear for the citizens of the old continent. Inclusion and exclusion of migrants and refugees are negotiated in the European Union and in individual countries regularly.

One going fear of terrorism, one of the worst forms of extremism, makes people all over the word be aware of human vulnerability. Fear as a result of unpredictable, senseless attacks linked to terrorism and extremism is renewed daily by global media and online networks. As Giroux (2003) suggests, "the rhetoric of terrorism is important because it operates on many registers to both address and inflict human misery" (p. 5). Also, Giroux (2003) and others have argued that governmental actions against terrorism are consistent with policies against youth and their problems that challenge the very assumptions on which law rests.

Recruitment of young people by violent extremist networks throughout Western countries is constantly increasing. Along with this increase has come a constructive discussion about teachers' training and programs that empower participants to respond to Media extremist propaganda. Emphasis on prevention is the key: it is vital to invest in interventions that aim to remove the breeding grounds for violent actions, to prevent these processes or stop them as early as possible.

The term Violent Extremism has become popular in recent years. Its emergence is closely related to the contentious nature of the term Terrorism. Practically all experts agree that the reasons for this failure have been political. Violent extremist attitudes are defined here as attitudes that "encourage, endorse, condone, justify, or support the commission of a violent criminal act to achieve political, ideological, religious, social, or economic goals" (International Association of Chiefs of Police [IACP] 2014). Research suggests that, terrorist groups strategically target young men and women for their purposes through the digital platforms.

Economic and financial crisis has disproportionately negatively affected Europe's youth with a rise of political and religious extremism, growing intolerance expressed by aggressive nationalism and ethnocentrism, propaganda and violent xenophobia. Such a risk of exposure to hatred and threats has expanded to keep with the polarization of the European society. Some drivers and symptoms of the politics of fear are, consequently, specific to particular regions or countries, however many exhibit some level of commonality across EU member states.

\footnotetext{
${ }^{1}$ Altheide, (2002), has extensively documented the expansive use of the word fear in news reports.
} 


\section{Teaching, Learning and Education}

Political extremist ideology is not principally controversial. No one who studies Political Extremism accepts that young people become followers of the Political extremist propaganda overnight, or that their embrace of extremist violent acts is caused by a single influence. Nearly all academic approaches conceive of Political Extremism as a progression which takes place over a period of time and involves different components and dynamics. Political extremist propaganda shaped by the "Politics of fear" come in many versions depending on the ideological scope. Far right-wing extremists and left-wing extremists, Islamic extremists and anti-abortion extremists could be identified under this large spectrum. It is not necessary whoever calls himself of herself a political extremist to be engaged in ideologically driven criminal activities. We must not consider all extremists as terrorists-some people, for many reasons, bear in mind extremist beliefs but do not resort to violence in an attempt to enact those beliefs.

It is not a surprise that, terrorists motivated by far-right extremism or by Islamist extremism share similar strategies, a similar barbarity, and a similar hope to re-create the global democratic order. However, it is important to recognize that different forms of Political Extremism exist today, such as "Nationalism", "Racism" and "Nazism".

Moreover, populist, nationalist and reactionary groupings are getting ahead by defeating democracy and challenging the open pluralistic European states based on the rule of law, free media as well as on human rights. Often these groupings gain support from the most vulnerable, the unemployed, the young and the outcasted. The inherent conflict at the heart of this topic is a fundamental clash between those who advocate the liberal values of openness, inclusivity and multiculturalism versus those who proclaim a closed, nationalistic and authoritarian society.

Within this framework, a major point of the Propaganda research is that decision makers, can shape perceptions of mass audiences and promote consent to state control measures (Ellenius \& European Science Foundation, 1998; Gerth, 1992; Jackall, 1994). On the other hand, while propaganda is not always accompanied by violence, it is associated with it.

Right-wing extremist content occupies the digital space, making a global internet audience of 4 billion people to come closer and closer to a violent ideology that undermines the values that democratic societies rest on-solidarity, equality and freedom. The right-wing Extremism and its propaganda are particularly worth in our consideration as, along with a history of violence, they have a very long online history, dating to the appearance of the public Internet in the 1980s (Anti-Defamation League, 1985). Right-wing Extremism typically supports a position including authoritarianism, anti-democracy and exclusionary and/or holistic nationalism. Furthermore, right-wing and xenophobic discourse increase and poses a serious danger to European security according to the OSCE (Organization for Security and Co-operation in Europe It is a commonality for Far-right politics to use a public discourse based on the politics of fear repeating frequently "we must put our people first", and "take back the missed control" from international organizations, such as the European Union (EU).

Nowadays, a prevalent mass-mediated hate-speech culture practically engulfs everyday life. Mark Warr found that the news media's emphasis of fear is consistently associated with 


\section{International Academic Conference on Teaching, Learning and Education}

MILAN, ITALY

children. ${ }^{2}$ Any response to the politics of fear must first recognize that it is a social construction that is linked to hate-speech propaganda produced by the mass media. Mass media propaganda is important in shaping public agendas by influencing what people think about ${ }^{3}$ and how events and issues are packaged and presented.

A unilateral propaganda megaphone is resounding from Far-right populist social media promoting charismatic leaders, disseminating "othering" ideologies, and eventually spreading the "politics of fear". Unsurprisingly, Neo-nazists are trying to lure to their campaigns and groups young people using Political Propaganda's powerful tools.

Discourse of fear turns into a usual tactic by various right-wing organizations merging with an expansion not only in the number of extremist websites but also in the abusive use of the Internet for diffusing propaganda, promoting 'virtual communities' of debate, fundraising, and organizing and mobilizing political campaigns. Far- right followers have customized digital Media and Internet technologies in ways that are innovative, sophisticated, and subtle. The aim is to reach young people with a world view of fear and instability. And the Internet is a growing significant front on the political struggle to contest the meanings of democracy, nationalism, and civil rights.

From their side, young people try in the complex European reality to discover their place, identity and belonging. Some of them risk to turn to extremist political groups where they wish to find alternative narratives of engagement, which are simplified by easy access to social media platforms promoting a sense of recognition and fellowship.

Indeed, police data on the biographical and socio- demographic characteristics of young offenders reveal that the groups of anti- immigrant and anti- foreigner activists are too heterogeneous to be easily called racists or right- wing extremists (Björgo, T. and Witte, R. 1993). However, the content of the far-right or far-left political activism has experienced important changes. A consensus definition of Political extremist Propaganda can't easily be produced, while violent attacks against innocents are absolutely beyond the pale, and contrary to our shared human values.

It is therefore urgent to confirm that we are able to contribute effectively to our students' understandings of these key topics when part of the language and symbols used involve the discourse of fear. In our opinion, it is never too late to initiate discussion among the school teachers and academic researchers that stir reflections on and make it possible to challenge dominant understandings of Political extremist Propaganda and its impact to young people, but also of other questions such as "what is a democratic school culture" or "what democratic qualities do we want to evoke in students".

\footnotetext{
${ }^{2}$ Mark Warr, 1992, "Altruistic Fear of Victimization in Households," Social Science Quarterly 73.4 (December 1992): $723-36$.
}

${ }^{3}$ D. L. Shaw and M. E. McCombs, 1977, The Agenda-Setting Function of the Press, St. Paul: West. 


\section{Teaching, Learning and Education}

\subsection{Defining Political Propaganda}

The range of political modernization (generalization of political participation) in 20th and 21st centuries gave rise to major revisions of the Political Propaganda's persuasive methods (Enzensberger 1981 and Demertzis 2002). In addition to fear effects, the constant use of Political Extremist Propaganda pervades crises and normal times.

However, it does mean that taken for granted the actual context of the politics of fear, the usual understanding of propaganda as the "management of collective attitudes by the manipulation of significant symbols" (Lasswell, 1927, p. 627) still stands. As noted previously, what has changed is the way this operation takes place as the digital technologies come with their own intrinsic features.

It should be assumed that propaganda covers the intentional sharing of facts, opinions, and ideas considered to change behavior or motivate action. While we usually think of propaganda as a historical term, scholars from both the social sciences and the humanities recognize it is at the same time as "a philosophical, psychological, rhetorical and sociological concept" (Cunningham, 2002) $)^{4}$.

Jason Stanley (2015) defines propaganda as 'the employment of a political ideal against itself (Stanley 2015, | XIII, italics in original) made in the service of a specific goal; that is, when ideals are misrepresented in such a way as to proclaim the very values being violated, from time to time even unconsciously.

In our paper, propaganda is understood as a flexible, adaptable, and overall more suitable term to refer to a wide range of messages that are on purpose created in order to influence the attitudes and behaviors of large groups of people. In doing so, we are aware that this new term is somewhat confusing in its connotation and denotation. According to the scholars of propaganda, the term does not necessarily have to be restricted to political contexts and totalitarian structures (Arendt, 2011).

With the application of the application of four interdependent principles propaganda could be considered more appropriately: "the determination to influence people's minds and behavior; the efficient use of mass media; the understanding of the psychological condition of the intended/desired audience; and the manipulation of socially established behavioral patterns " (Jowett and O' Donnell 2015). In addition, propaganda is a phenomenon adaptive to different social contexts (Jowett and O' Donnell 2015: 391); it is adaptive to the media it utilizes, trying to make the most from their structure and operational culture to help its goals. Indeed, with the development of digital platforms from websites to social media environments, new modes of propaganda have emerged. "The media form propaganda, whilst propaganda forms the media and modem societies "(Pleios 2011).

\footnotetext{
${ }^{4}$ Cunningham (2002) notes that because propaganda can be truthful or full of lies, its defining feature is its indifference to truthfulness.
} 


\section{Teaching, Learning and Education}

\subsubsection{Propaganda, post-truth (new [media] propaganda)}

It has become popular to hear about new terms such a 'post-truth' and 'fake news', even though they actually describe old phenomena. Among other things they indicate the wide interest of societies in the study of media communication and propaganda strategies. As with propaganda, which, due to its historical use by totalitarian regimes developed negative connotations, the term "post-truth" refers to a typical negativism due to its presence in the public domain following the propagandistic campaigns of Trump and those political representatives who campaigned for Brexit. Henceforth, the very use of the term post-truth -as with that of its antecedent, propaganda- has been propagandistic in nature. We pay particular attention on the need to always bear in mind that the term propaganda and its contemporary equivalent, posttruth, denote a fight between ideologically different borders for the body of knowledge available in that field (Snow and Taylor 2009). For the most part, only single case studies can be classified under the strand of the influencing potential of fake news, in part because it has been so difficult to find a common definition (Edson, Lim, \& Ling, 2018).

With the rise of the so-called fake news, typologies and labeling systems have been encouraged to describe and define the many forms of such news guided by the domains of facticity and intention.

\subsubsection{Political extremist Propaganda}

Taylor (2003: 321) argues that 'whether we will call a piece of information propaganda or not, depends on the side we are' and similarly. Bernays (cited in Sproule 1997: 57) asserts that 'the information we believe in is education; the information we don't believe in is propaganda'. As it happens with other forms of Propaganda, Political extremist Propaganda refers to the use of emotions, taking advantage of sentimental factors, and assist the intentions of the propagandist through disseminating an extremist ideology or doctrine. One way to deconstruct its impact, as we have done in DEMOKLEOS workshops, is to analyze in a simple way even to school students an extremist Propaganda campaign or ongoing effort. It is useful to present different narratives including youth appeal, appeal to maturity, appeal to teenagers, young children, men, women, professionals, specific religious groups, or imagined or real hate groups.

Diverse extremist groups, from ISIS to right-wing nationalists, now are using the digital space to targeting specific viewers to spread pictures, slang, music, and cultural meaning that could be accepted by any adolescent targeted. There are a variety of evolving approaches to using use data science methods to identify segments of a population that are receptive to specific propagandistic content and ideas.

Political Propaganda is closely connected to the long development of professional political communication that, as a reaction to the modernization of politics, has, in both democratic and totalitarian regimes, conceived of a good deal of citizens as risks to be handled (Keyes 2004; Harsin 2015: 331).

Algorithmic dissemination of content and the evasion of traditional media filters and opinionformation porters, make Political extremist Propaganda spread faster, influence deeper, be more ardently charged, and most significantly, be more resilient due to the authorization bias that online echo-chambers allow and support. 


\section{International Academic Conference on Teaching, Learning and Education}

MILAN, ITALY

A study of the European Parliamentary Research Service (EPRS) shows ${ }^{5}$ that interactions between artificial intelligence and democracy already affect the legislative, executive and judiciary powers, the relations with citizens and media, security and defense. The study highlights the fact that the new technologies bring threats and opportunities at the same time. Among the threats there are computational Political extremist Propaganda techniques such as algorithms on social media and search engines, bots, trolls, sphere phishing, distributed denial of service, brutal force attacks on internet of things devices and digital technology.

It is obvious that Political extremist Propaganda is adapted to the newer forms of political expression, mobilization and engagement. Not to mention once again that extremist propaganda gives young people feelings of being involved in something "greater" than the self.

Political digital propaganda," is an effective non-military means for achieving political and strategic goals, in a way that exceeds the power of force of weapons" (cited in MacFarquhar, 2016). In other words, the weaponization of information via digital propaganda is considered by some states as the finest apparatus for correcting power asymmetries in their global standing. This comes as no surprise that several studies describe the increasing youth support for (populist) far right propaganda (e.g. Steenvoorden and Harteveld 2018) and designate the mobilization of far-right movements in Europe and internationally (Peterson 2016).

This comes as no surprise that several studies describe the increasing youth support for (populist) far right propaganda (e.g. Steenvoorden and Harteveld 2018) and designate the mobilization of far-right movements in Europe and internationally (Peterson 2016). For hopeless young people, far- right Propaganda is a remedy for loneliness by making them feel emotionally attached to beliefs, opinions and ideas. Adolescents, in particular, are exposed to dramatic and often propagandistic messaging in different forms, for example on digital space or in viral videos, and have to choose through professionally constructed blogs with the purpose to influence their thinking. That is why the topic of propaganda- understanding its forms and methods-is essential to be used by teachers hoping to strengthen the critical idealism of their students.

In a post-truth word, Media Propaganda Education matters as it could consist one response to the actual state of our complex, interconnected word and activate cognitive, social, and affective reasoning, reflecting on shared values which peaceful democratic societies may be built. In the difficult reality described above, the knowledge of Media Propaganda Education, plays a key role in building a culture of democracy and a culture of human rights, which are the foundations of our democratic states.

\subsubsection{Media Literacy Education has its Roots in Propaganda Education}

Undoubtedly, critical Media Education plays a crucial role-both in analyzing spin and propaganda, and conversely in recognizing the importance of media in freedom of speech and critique.

5 https://www.weforum.org/agenda/2017/01/what-emerging-technologies-have-the-biggestnegative-consequences/ 


\section{Teaching, Learning and Education}

Many have argued that Media Literacy efforts are needed for youth to fully take advantage of digital opportunities, related to the spread of disinformation and propaganda. The study of advertising and propaganda has long been a part of Media Literacy Education and it is very likely that the vigorous propaganda education programs that developed in the late 1930s in the United States had an influence on the known practice of media literacy during the late 20th century (Hobbs \& McGee, 2014). Based on Media Literacy, youth and adults alike begin to understand their relationship with media, which is the conduit through which we engage with society at large.

Thanks to the blowout of Media Literacy ${ }^{6}$ globally, and the urgency that is now being granted to media literacy education, school children are becoming more vocal champions and enablers of Media Literacy - as experts of social media, they recognize the standing of Media Literacy more than many adults, regardless of their geographic location. For the purposes of our paper, we define Media Literacy as the "ability to access the media, to understand and critically evaluate different aspects of the media and media contexts and to create communications in a variety of contexts" (European Commission, 2007).

Despite the fact that online environments are now central to Political Propaganda, Media Political Education in schools is virtually nonexistent. In the vast majority of EU Member States, there is no provision of formal teacher training in Media Literacy or Media Propaganda Education.

Working with school students and teachers, participants at the Erasmus+ KA2 DEMOKLEOS project coordinated by the Directorate of Secondary Education of Piraeus, has showed that the 21 st Century competences of Media Literacy are the competences that provide citizens with the base of knowledge that they need to be effective participants in an increasingly complex life and work environments. Having these competences and knowing how to apply them, they are being oriented from their young age towards Democratic Awareness (see Erasmus+ KA2, DEMOKLEOS project) and they lead to a better understanding of the impact of disinformation and propaganda on democracy. Competences alone are no guarantee of Democratic Awareness because creators of Media Political Propaganda are holding very high levels of competences in media literacy.

We were not surprised that the teachers and students, participants at our European funded project, had never heard about Media Propaganda Education but they could recognize easily the connection between Media Literacy Education and Propaganda Education. They reported that all time, they were obliged to deal with the impact of such topics on classroom learning, especially in subject areas that are especially prone to propaganda such as science, literature, history and citizenship education. Also, they were not used to sharing their experiences with colleagues and reflecting on their own practices.

\footnotetext{
${ }^{6}$ Borg and Lauri (2011) note that without a satisfactory translation of the word 'literacy' in French, the language uses the word 'education' in place of 'literacy' ('éducation aux médias'). In German, 'media literacy' is translated into a general term for competence ('Medienkompetenz'), while in Dutch, the concept is referred to as 'media wisdom' ('mediawijsheid).
} 


\section{Teaching, Learning and Education}

Taking into account, the real needs of the teachers, we found better to create sustainable pedagogic interventions and a longer-term planning during the implementation of the project which lasted three years (2015-2018). This successful implementation was empowered by an exchange in mindset that associated the roles and identities of teachers and students, and the setting of professional development became a combination of physical and virtual networking.

By entering into the area of Media Propaganda education, we are invited to think about the power of communication and our responsibilities as both authors and audiences. Consideration of new forms of propaganda allows to review questions about the use and potential impact of new media and technologies. At the same time, we must not omit, misinformation, disinformation, partisanship and conspiracy theories since they consist tools of Media Propaganda.

Media Propaganda Education is needed more than ever in Secondary School Education because it links identity, culture and language to young digital natives using social media as part of their everyday life. In this context, Media Propaganda operation is significant to be plenty understood. It could be often confused with a more instrumental view of media and technologies in schools (for example, using media and technologies to teach about disciplines like languages, sciences, history etc.) or also with developing information technology procedural skills. The topic of Media Propaganda Education is important because of various indicators and studies that tell us that the level of critical thinking about media is extremely low, whereas the content creation skills are very high. More precisely, young people possess technical skills to use the media but do not have a critical awareness of them.

On- line political propaganda and extremism is a real challenge when we have to do with children trying to filter what's real and what's not. The war in Syria, Israel-Palestine, Donald Trump - whatever is in the media comes up in school from the internet. School students, participants at the DEMOKLEOS project, mentioned that they don't want to watch the news but they get whatever information they like from the internet. In addition to contributing to the development of critical thinking, media literacy also helps students connect the material they learned in the class with real-world examples, which brings real life into the classroom.

Particularly, understanding far-right Media Propaganda as a gradual process reveals that there is no such thing as a common profile or pathway. As we observed during our own field research ${ }^{7}$ conducted at the schools of the municipalities of Piraeus, Greece, social media campaigns launched by far-right groups, can be driven by a combination of pull factors (how are school students tempted/recruited?) and push factors (what are intrinsic drivers?) as well as major life events.

As the overall aim of the Erasmus+, KA2 project DEMOKLEOS is to provide educators with the necessary tools, mainly through open training activities, aimed at facilitating the identification of 'political extremist' motivated hate communication. For this purpose, a communication-based training concept has been worked out, for teachers of the Secondary Education working in different European countries and for their school students. Specific forms

\footnotetext{
${ }^{7}$ Presented at the Institute of Education of the University of London, June 2016.
} 


\section{International Academic Conference on Teaching, Learning and Education}

MILAN, ITALY

of Political Literacy education had been elaborated, which provide skills to analyze the media and political propaganda, but also enable critical idealism to be fostered.

\section{Context of the evidence}

One of the pillars of combating antidemocratic ideologies and practices in education is working together with international partners.

DEMOKLEOS, The KLEOS of Democracy in European School, Rethinking Democratic Awareness and Collective Responsibility for a Whole Approach ${ }^{8}$, was a 3-year Erasmus+ KA2 project (September 2015 - August 2018), Partnership in School Education within the scope of the main action: "Cooperation for Innovation and Exchange of Good Practices".

It involved 10 partners in Secondary and High Education coming from North to South Europe: from Finland and Germany to Greece, Portugal, Turkey and Cyprus. The Coordinator of the Project was the Directorate of Secondary Education of Piraeus and the Consortium was consisted of school partners, three Universities and a Finnish NGO.

DEMOKLEOS was not only focused on Media Propaganda Education. It took into consideration that in European public debates, there has been much talk of apathy, a democratic deficit, young people turning away from politics, declining voter turnout and decreasing membership of political parties. However, there is also real evidence that people can be mobilized to participate even in this 'apathetic' age by using new information communication technologies (ICT). ICT can be used to provide input, bring political processes closer to the citizens and serve as a tool to actively follow events and issues (Kukovic and Brezivsek 2014). In E.U. and elsewhere young people are becoming increasingly disengaged from politics however recent studies suggest that young people recognize the need to be more informed and are interested in a broader political agenda. Nevertheless, there is overwhelming evidence to show that younger citizens are not apathetic about 'politics' - they have their own views and engage in democracy in a wide variety of ways that seem relevant to their everyday lives (Norris 2003). Moreover, one of the specific objectives of the project was to raise awareness on issues such as political propaganda, indoctrination and fake news found in the online environment and the influence of social media on politics and civil society.

The High schools taking part in the Consortium have been empowered to constructively tackle these challenges: schools in Cyprus, Finland, Greece, Portugal and Turkey have implemented several local and international projects to prevent political extremism and build peace among

\footnotetext{
${ }^{8}$ A whole school approach in our Erasmus+ project can be defined as a holistic approach to education. The approach involves all members of the school community, including school staff, students, parents, social workers, youth services, NGOs and the broader community - working together in promoting a sense of belonging and cohesion. The entire school community engages in a cohesive, collective and collaborative action, based on multidisciplinarity and on differentiation (European Commission, 2015).
} 


\section{International Academic Conference on Teaching, Learning and Education}

MILAN, ITALY

youth. More than 5000 young people in the partner countries have participated in the school projects adapted to their needs and overseen by their teachers and academic researchers.

The overall objective of the project was to empower teachers, young people and their parents to better understand and recognize complex challenges contributing to the formation of young people's democratic values, active democratic citizenship, political literacy and social agency.

Concerning Media Political Education, the evidence coming straight from the project told us that is also about teachers and their school students, education and own wellbeing as it leads to more competent, more confident, more satisfied teachers. One of the most important goals of the project was clearly directed to teachers: they need to be empowered and trained to be able to counter extremism, indoctrination, to respect the needs of students of diverse origins and safeguard common fundamental rights based on mutual respect and acceptance of diversities.

2.1. In the wake of the "Paris Declaration on Education for fundamental values of tolerance, non-discrimination and inclusion", DEMOKLEOS was submitted

DEMOKLEOS adventure began following the Paris Declaration, which emphasized the role schools can play in countering extremism.

Just after the Charlie Hebdo attack, in March 2015, the EU Education Ministers and Commissioner Navracsics adopted the Paris Declaration on 'Promoting citizenship and the common values of freedom, tolerance and non-discrimination through education". This declaration showed Europe's determination to stand shoulder to shoulder in support and safeguard of the fundamental values that lie at the heart of the EU: respect for human dignity, freedom, democracy, equality, the rule of law and respect for human rights.

The Directorate of Secondary Education of Piraeus by its responsible for the European and International Affairs, Dr Constantina Spiliotopoulou, responded by submitting the DEMOKLEOS, Erasmus+ KA2 project in School Education at the end of the same month following the priorities of the Paris Declaration which called for enhancing policies ensuring that young people acquire social, civic and intercultural competences by promoting democratic values, fundamental rights, inclusion, non-discrimination, active citizenship and competences of critical thinking and media literacy, especially in the use of social networks, so as to develop resistance to all forms of discrimination and indoctrination.

Statements such as the Paris Declaration show the extent to which there is growing concern among political decision makers at the highest level regarding the direction of democratic development in both the European Union and individual societies in Europe, and regarding the role young people have in those developments.

\subsubsection{DEMOKLEOS genesis: an urgent to need counter Neo-Nazism in Secondary Education}

The genesis of the project stemmed from a common need felt by European teachers for empowerment in their field of action regarding misguided trends of democratic deficit which may affect the prosperity of European Democracy: hate crime, racism, discrimination, political 


\section{Teaching, Learning and Education}

and social extremism, all being threats to social wellbeing and to the respect of European values. At the risk of falling prey to historical amnesia, the crucial lesson which has been learned is that the ideology, values and institutions of a liberal democracy are once again under assault by those who no longer believe in equality, justice and democracy.

Through training and activities in different countries based on the intellectual outputs of the project, teachers and school students realized that the political contexts have changed considerably. DEMOKLEOS had to respond to these changing contexts, and develop innovative approaches and tools to provide sustainable strategies of prevention of the increasingly complex phenomenon of polarization that may exacerbate extremist ideologies which might lead to violence.

In fact, the project encouraging teachers to address political aspects, supported actions that aim to foster the development of social, civic and intercultural competences, online safety and digital well-being, and tackle discrimination, political propaganda, violence, fake news and other forms of online misinformation. We had tried to focus on the important questions of Political Literacy in education: how to assist learners in their development of political orientations and behaviors in support of human rights and peace.

Our analysis needs research at the beginning of the project, pointed to growing tensions emerging from the affective dimension of far-right rhetoric in classroom spaces, increasingly pronounced political extremist orientations as well as violence motivated by hate speech towards various groups. It was clear that school students in the partners' countries are exposed to many of political extremist ideas, whether through the media, or through online connections.

Particularly, in 2015, the propaganda of the Greek neo-Nazi party Golden Dawn through online social media networks explicitly evoke Nazism. Greece, however, is the first Western European country to have seen a far-right movement with neo-Nazi characteristics becoming one of the major opposition parties in its parliament.

Two years before, members of the party killed the anti-fascist singer Pavlos Fyssas, who was an old student at one of the Piraeus High schools belonging to the network "DEMOKLEOS". The offices of Golden Dawn in our city, Piraeus constituted the base of operations of multiple criminal activities of the organization. Between 2017 and 2018, the total number of hate crimes, with members of the Golden Dawn often responsible. grew from 102 to 117, while the number of attacks targeting refugees and migrants more than doubled.

Our own field research which was presented outside Greece in Britain, revealed an amazing professionalism concerning recruitment and indoctrination inside the schools. The results indicate the professional way by which Golden Dawn, as other Neo-Nazi parties, developed programs and structures that particularly attract children not yet of voting age, at schools or holiday camps. Our data drawn from the conducted interviews gave voice to targets' experiences of face-to-face and more widely broadcast Neo-nazist hate speech, and outline the constitutive and consequential harms they claim to have suffered.

At the same time, in Piraeus and other parts of Greece, Golden Dawn had invaded schools, boys and girls in order to staff the organization's hit squads. Neo-Nazi propaganda on social media had a much larger impact than the mainstream political parties. Copying other neo-Nazi one 


\section{International Academic Conference on Teaching, Learning and Education}

MILAN, ITALY

line for a, they exchanged their ideas, denied the Holocaust, disseminated hate music and stirred up hatred against immigrants and refugees arriving to Greece. Once again, as was documented from our research young people 's problems of everyday life like relationships and school related topics were also discussed. Golden Dawn's organizations when they addressed to youth, they camouflaged their propaganda of no respect for human rights and democracy.

By adapting its narrative to the youth, developing youth mobilization strategies and striking political alliances with young groups of other far- right-wing European parties, Golden Dawn made its way to a position of great influence in Greek schools. In the municipalities of Piraeus, reprisals against teachers and school students who denounced the action of Golden Dawn were a common phenomenon. Greek authorities alleged that even while holding seats in the national parliament, Golden Dawn operated as a criminal Organisation.

Greek neo-Nazis were and are under constant pressure from the democratic society. As a result, far -right Golden Dawn suffered a devastating defeat at $7^{\text {th }}$ July 2019 general elections with no parliamentary representation. Greek voters reversed a trend towards extreme-right politics that has been prevalent in some other European countries.

Despite the shrinking of its voter base, Golden Dawn still remained relatively popular with young Greeks, capturing as much as 11 percent of the votes of citizens between 14 and 24 years old in the country.

In order to deal with this phenomenon successfully, DEMOKLEOS had to be implemented on various levels. The International Steering Committee of the project agreed that in the fight against any form of political extremism, the focus should be on prevention through education and awareness raising, and early reaction, at grass-roots level, to any manifestations of neoNazist propaganda and other propaganda, whether violent or not. It was agreed to approach prevention through humanistic, relational and inclusive pedagogics. This is where Media Propaganda Education came in.

Media Propaganda Education in school was taken into consideration as well as the design and implementation of youth policies and the role of the media developing a Neo-nazist lifestyle and their impact on public discourse. Finally, a serious threat gaining our attention in connection with recent dramatic events was the increased radicalization and mobilization potential of the Internet. Extremist groups use the internet/ social media to influence young people and recruit new members (online radicalisation).

Thus, in this paper, the experiences mentioned below are referring to the implementation of the DEMOKLEOS pilot project concerning the training of school teachers and students concerning the part of Media Political Propaganda and not other training offered on different other topics.

\subsubsection{The training program}

STARTING POINT: While exploring concepts and the content for the basis of the training programme and the entire project, a need for further research arose on the causes or factors contributing to the development of extremist violent behavior in youth. 


\section{International Academic Conference on Teaching, Learning and Education}

MILAN, ITALY

Depending on the type of (sectorial) training sessions offered, information is also provided in relation to: - the local context; - legal frameworks; - privacy issues/sharing information; • specific school issues; • good practices of counter-far-right propaganda addressed to young people.

Such type of training is generally offered in a very practical and interactive way, making use of case studies, assignments, audio-visual material and toolkits.

In a theoretical sense, the training relies on a wide range of theories and concepts. For all the topics (not only about Media propaganda Education) concerned and the material for the project's intellectual outputs and training sessions, in order to clarify the theoretical and methodological premises of the design, we decided to elaborate a conceptual framework useful to identify possible learning objectives with an emphasis on the development in adolescence and specific needs for connectivity, autonomy, and competence.

The part of the training dedicated to Political Literacy which covers topics such as learning and teaching democracy, human rights, stereotypes and prejudices and media literacy, also relies on many documents and theories. The documents include the Paris Declaration (March 17, 2015), the Universal Declaration of Human Rights, the European Convention for the Protection of Human Rights and Fundamental Freedoms, the Council of Europe Charter on Democratic Citizenship and Human Rights Education, and the publication of the Competences for Democratic Culture (Council of Europe, 2016). These documents have been plenty used by the users of the DEMOKLEOS project, both nationally and during the international meetings.

The theory of media literacy is dealt with through the definition of the European Commission (2013), which defines it as an intersection of three important areas: the use of skills, critical understanding and communication skills.

Our training sessions aimed to:

- raise awareness and understanding of the process of political propaganda and extremism in general and in the specific context of Media;

- help teachers of the Secondary Education recognize some of the signs displayed by vulnerable school students at risk;

- empower teachers with the tools and instruments they need to respond appropriately;

- as DEMOKLEOS was a Consortium of European partners was considered necessary to create international collaboration partnerships and early intervention to protect and divert young people away from the risks they face.

In most cases, teachers of DEMOKLEOS project reported they do not feel competent to teach Propaganda or Prevention of Extremism, and for several reasons. One of them is that in order to teach human rights, active civic engagement and intercultural and inclusive practices, a teacher needs to possess extensive knowledge of various social and natural sciences, but also excellent communication skills in analyzing, conducting discussions and teaching such controversial and sensitive topics. (Guerin, van der Ploeg i Sins 2013). 


\section{Teaching, Learning and Education}

Participants from a specific country cited knowledge of schools seeking to limit any teaching that could ostensibly be linked to politics, including diverse world views, thus explicitly undermining the notion of democratic education.

Surely, young Finnish White Power radicals or German and Greek Neo-Nazis acting inside the schools and the Universities, as testified in several cases the teachers participating to the DEMOKLEOS project, need highly experienced practitioners and well-informed teacherswho are independent from state policies ${ }^{9}$.

Staff aren't prepared for the possibility. The vast majority of staff don't want to teach Political Propaganda or Extremism and don't know how to respond when kids say something provocative coming from an extremist ideology or unexpected. Besides saying 'this is against the school rules', which doesn't actually challenge what the child believes, they feel they can't say anything. So, my students carry on with the same view. (a teacher, Finland).

Teachers who know how to teach democratic values, but who also live values such as acceptance and respect, equality and human rights, strongly contribute, not only to the prevention of Political Extremist Propaganda (Davies 2009; Webber 2011; Pels and de Ruyter 2012) but to other difficulties their students may face.

If we consider the challenges posed to the education system today, the question arises as to whether teachers are prepared and trained enough to deal with issues of diversity, violence and even potential youth recruitment. There is a lot of relevant research (Buijs et al. 2006; Sageman 2008; Slootman and Tillie 2006; Kepel, Khosrokhavar and Roy 2005) describing young people's vulnerability to prejudice, discrimination and radical attitudes and behaviors, as well as their teachers' insufficient skills in recognizing these problems and dealing with them (van San, Sieckelinck and de Winter 2014). There is a high risk, therefore, that there will not be a proper response within the school system when it comes to a certain type of risk behavior of the young people today.

Here we are talking about personal and social competence and about civic education. If we want to educate children and young people as responsible citizens who are acquainted with their rights and laws and policies, and who respect the rights and beliefs of others (Davies 2009, Webber 2011), it is important to provide them with such education, which will make them resistant to any kind of extremism (Pels and de Ruyter 2012), but also to other negative impacts.

Teacher training may be a key area here, enabling the development of skills and orientations towards analyzing the discourse of Media Propaganda. It requires innovative pedagogical concepts and approaches that address adults' critical thinking skills in terms of information received through media, politicians and further opinion makers. It poses an additional challenge to reach out to the student audience particularly vulnerable to misinformation or fake news.

\footnotetext{
${ }^{9}$ Spiliotopoulou Constantina, 2018, Extremism and Prevent: the need to trust in Democratic Awareness and Political Literacy in School Education. An Information Guide for teachers, ed. Directorate of Secondary Education of Piraeus, p. 13.
} 


\section{International Academic Conference on Teaching, Learning and Education}

MILAN, ITALY

Unlike national-level training programs, DEMOKLEOS training program attracted teachers from the partner's countries with a considerable range of teaching experience, most already working in classrooms in various settings. Teachers coming from different academic disciplines and activities were designed to include synchronous and asynchronous exchange.

Any training program aimed teachers from different countries working together will, therefore, need to help teachers examine and reflect on their values, and how these relate to their professional context. Given such diverse contexts, teacher training programs cannot possibly adopt transmission-style pedagogy, when, as teachers in Hacohen's study point out, 'the norm is a flux of change' (Hacohen, 2012: 120). Simultaneously, the student body on the (largely online) Erasmus+ project, formed via a Moodle platform an invaluable resource in the development of teachers in an international, intercultural and multilingual context. Via the Moodle, students and teachers engaged in virtual collaboration between the participating schools in order to create a deeper understanding of and insight not only about Media Propaganda Education but into the key DEMOKLEOS topics. Moodle helped also to exchange expertise between teacher and student.

The main goal of DEMOKLEOS training program on Media Propaganda Education was to strengthen and develop the competences of teachers, and principals in a range of areas, such as: communication and relationships, dialogue (with emphasis on controversial topics such as propaganda and extremism), democratic processes, media literacy, conflict resolution and violence prevention. This approach involves raising awareness among first-line practitioners working with vulnerable individuals or groups at risk of violent behavior as extremists in order to ensure that they are well equipped to detect and to respond to Media Propaganda.

Throughout the two year-long training program, weekly reflective discussions take place via Moodle on a variety of topics concerning Media Propaganda Education, many of which are either explicitly linked to Political Literacy or develop such links through student contributions. All participants considered themselves to be highly interested on the issues of Political Extremism and Propaganda affecting the school community. Ten participants from the 85 cited knowledge of schools seeking to limit any teaching that could ostensibly be linked to politics, including diverse world views.

\subsection{Introductory workshops for teachers on extremism}

In the first session, teachers were asked to share their experiences from the classrooms on the issue at the beginning of the workshop. They offered different but complementary insights into the practical difficulties and potential strategies for covering an innately difficult topic.

"Extreme views are bound to happen with a thousand people (in the school) ...Extremism may come from the point of ignorance, but they are willing to change their opinions. "(a teacher, Turkey).

"Our students of lower socioeconomic status are often exposed to the propaganda of the neonazi party Golden Dawn. Being in the same class with children from different nationalities causes fear, caution, and distrust for them. A large number of cases of peer violence is motivated 


\section{International Academic Conference on \\ Teaching, Learning and Education}

MILAN, ITALY

by hatred towards members of other ethnic or religious groups". (a teacher of a Greek Vocational High School).

"I think it brings challenges in the fact that a number of our student's don't see the world outside of (this town) .... They're very kind of set on what they hear, what they're told, with regards to extremism and the things that happened in Europe recently. There are quite a few of them that will just have that whole idea of 'well, every Muslim is a terrorist' because they just haven't lived amongst Muslims and they haven't lived amongst other nationalities so it is hard to make them see that there is a bigger world out there" (a teacher from a private High School, Nicosia, Cyprus).

We had found important during the second session therefore, to distinguish between the defining properties of right-wing extremism/radicalism and the accompanying ones, and in so doing we had advanced a minimal definition of the concept as an ideology that encompasses authoritarianism, anti-democracy and exclusionary and/or holistic nationalism.

$3^{\text {rd }}$ workshop

- Make your students perceive extremism as a historical phenomenon, corroborate this opinion by some examples from the past.

- Ask students after searching on the net to deliver alternative narratives: offering their own alternatives to extremist propaganda and worldviews either online or offline make them active citizens.

$4^{\text {th }}$ workshop

- Associate extremism with violence, hatred, religion, or racism, followed by xenophobia and a lack of tolerance to other people's views.

- What is the ideal society according to violent extremists? What are they fighting for? Who are the enemies/scapegoats?

$5^{\text {th }}$ workshop

- -Interpret extremism in a wider historical geopolitical context

- What are the differences between a extremist form of an ideology and a more moderate, mainstream version?

- What are the differences between orthodox and radical varieties of an ideology?

At the end of the fifth workshop we asked the teachers to come back to their classrooms and bring us their feedback. The trained teachers reported that although the students were acquainted with extreme worldviews, political groupings, geopolitical events, and events, they did not link them with extremism.

\subsubsection{Introductory workshops for teachers on Propaganda}

We found necessary to start with:

- Pedagogical guidelines and standards to teach Controversial issues. 


\section{International Academic Conference on Teaching, Learning and Education}

MILAN, ITALY

Teachers agreed they should use interactive pedagogical strategies, but did not feel prepared to use them. That's why such complex issues as Propaganda and Extremism are often approached rather superficially and one-dimensionally.

At the end of the workshops they confirmed that exploring controversial texts, students acquire the tools of rational thought by which they can approach, analyze, and debate controversial issues in a forum of mutual respect and understanding.

While the impact of propaganda is, of course, a notoriously difficult variable to measure, we have been careful not to confine its scope only to the digital sphere.

All the teams were involved in different activities that offer answers to the following important questions:

What is Propaganda? Distinguish fact from opinion.

In which forms appears Propaganda?

Propaganda characteristics

- Where is Propaganda Found?

- Propaganda and Post-truth

- What is fake news and how is it different from propaganda?

- Recognizing Media far right Propaganda Techniques

- Analysing Media far right Propaganda with Key Questions of Media Literacy

- Conceiving of the visual propaganda as a means of state-driven education of the youth population. What we know about the actual state-sponsored propaganda?

The state-sponsored propaganda has exploded with the rise of social media and the numbers are staggering. ${ }^{10}$

1 workshop for teachers on the Media Education Conceptual Framework: The European Digital Competence Framework for Citizens (DigiComp).

\section{3 workshops for teachers on Content analysis}

\section{Introduction}

We asked teachers from the different countries to comment "in the contemporary context, the spread of disinformation does not create intolerant worldviews; rather, intolerant worldviews are what allows disinformation to spread". ${ }^{11}$

\footnotetext{
${ }^{10}$ Lang, M. (2017, Nov 1). Number of Americans exposed to Russian propaganda rises, as tech giants testify. Retrieved from http://www.sfchronicle.com/business/article/Facebook-Google-Twitter-say-150-million12323900.php[
}

${ }^{11}$ Found in: Hyman, I. E. \& Jalbert, M. (2017). ,Misinformation and Worldviews in the Post-Truth Information Age: Commentary on Lewandowsky, Ecker, and Cook'. Journal of Applied Research in Memory and Cognition, $6(4), 377381$ 


\section{International Academic Conference on \\ Teaching, Learning and Education} MILAN, ITALY

Media Content Analysis aimed to identify ${ }^{12}$ :

- Points of the far-right ideology • Omitted information - Intended youth audience - The purpose of the story $\bullet$ Facts vs. opinions $\bullet$ How media propaganda is constructed.

1. Case study: Left and right populism (qualitatively different forms) as a "response" to the strict/austerity policies implemented by the EU.

2. Content analysis of "interview bites" (statements by journalists, politicians, experts, civilians) in articles referring to the EU financial crisis and the immigrants/refugees issue (mainly from 2016 and 2017).

3. Working on formalized Web content analysis of 336 far right-wing websites.

Our teachers in different countries have been working on 336 far right-wing websites. We had compared different types of far right-wing groups which compose the radical right family (from political parties to associations), underlining the main differences and similarities across groups and across countries.

The various specificities of the usage of the Internet by extreme-right organisations have been demonstrated and linked to offline reality.

Briefly, the data - analyses consisted of a range of genres including party programs, newspapers, TV documentaries, posters, interviews, merchandize, online propaganda, photos, speeches and election campaign materials.

\subsubsection{Workshops for students on deconstructing Media extremist Propaganda.}

"There is too much propaganda that stands out - all bad news, political quarrels and wars; politicians arguing with each other, TV- channels are subordinated to the parties". (a school student, Greece)

\section{$1^{\text {st }}$ workshop: Deconstructing Media extremist Propaganda}

\section{Methods and material}

Advertising posters and websites, intended to disseminate political ideas and educate the youth population.

\section{Questions to Start the Conversation in the class}

- Have you seen any type of extremist propaganda online? What did you notice about it?

- How do you think extremist propaganda is like advertising and how is it different?

- What do you know about terrorism and extremism and what more do you want to know?

${ }^{12}$ Adapted from: Hobbs, R \& Frost, R. (2003). "Measuring the acquisition of media-literacy skills". Reading Research Quarterly, 38, 330-352. and Weber, C. (2012). News literacy assessment (Report prepared for The Center for News Literacy). Retrieved from http://drc.centerfornewsliteracy.org/sites/default/files/resource-files/2012assessment.pdf. 


\section{International Academic Conference on \\ Teaching, Learning and Education}

MILAN, ITALY

- Why do you think members of extremist groups reach out to young people online to recruit new members?

- How do you feel about extremist groups trying to recruit young people online?

Briefly, deconstructing Media extremist Propaganda is to deconstruct stereotypes relating to race, gender, disabilities and sexual orientation, and make young people and minorities aware of how new media misrepresent them;

2 Workshops for students on e-engagement: coherently with Media Propaganda Education perspectives, which emphasizes people's empowerment rather than media censorship, the aim is to play on a participatory and active approach to promote children's voice appropriation and political literacy skills;

The workshops for students addressed crucial aspects of media literacy that are often overlooked, such as strengthening participants' emotional intelligence and coaching participants to share their new knowledge with family, friends, and colleagues.

\section{Activities}

Note that the learning goals for each activity reference the fundamental competencies of media literacy, including the practices of accessing, analyzing, creating, taking action, and reflecting (Hobbs, 2014).

First activity:

Engage with the definition of propaganda by examining Political Propaganda posters from different countries and periods of the 20th century.

At the beginning of the training, school students were confident - even arrogant.... At the end, they had grown cautious towards the information they consume.

Second activity: Virtual exchange via Moodle

Virtual exchange via Moodle between students of the participant's countries to better understand how Media Political propaganda messages are interpreted and how they inform and guide the civic actions of young citizens. We conceptualized virtual exchange via Moodle as an empowering process that enables learners to encounter the other in a safe environment while simultaneously reflecting upon one's own culture and values.

The virtual exchange contained of a variety of digital media platforms, texts, and technologies to support the cross-national comparison of contemporary Political Propaganda addressed to young people. 


\section{Teaching, Learning and Education}

\section{Conclusion}

\section{Lessons learned}

When providing awareness via a training program, one of the most important lessons is that language is important. It is important in two senses: having a common set of definitions among professionals is fundamental, as is avoiding terms that may offend the target group and/or national educational policies. Speech matters - and it is important to promote inclusive language on a Political literacy level, and to resist divisive discourses of any kind.

Focusing on vulnerable school students who may be at risk (instead of talking about neo-Nazists or violent extremists), safeguarding and protecting them instead of criminalizing, are key. Additional lessons learned encompass the personality of first-line teachers' participants of our DEMOKLEOS project, training forms and materials, and how by expressing opinions, creating and commenting on Media extremist Propaganda, adults and adolescents build citizenship skills that advance democratic goals.

Another lesson we learned is that part of the training must focus on the demeanor of school teachers such as:

- having a curious attitude and not being afraid to ask (open) questions;

- not judging or moralizing their students;

- $\quad$ engaging with colleagues and organizing case discussions. As Nikos, a school teacher from a Greek Vocational High School mentioned: "All countries in Europe face the same issues. Organizing case discussions about current extremist propaganda during DEMOKLEOS training sessions with other teachers from different countries and [seeing] their commitment made me feel a lot less alone and discover real effective pedagogical tools";

- $\quad$ using the skills already used in other situations by looking at the situation as 'business as usual',

- asking help with any type of school student at risk;

- daring to share uncertainties with fellow colleagues, school leaders and/or educational experts - a teacher can't help in all the cases.

Concerning the training forms and materials the gained experience showed that the following approaches can usually be effective:

- an interactive and practical approach in addition to some level of theoretical framework;

- case studies of common interest and sharing experiences;

- using up-to-date information related to the local and international situation, like newspaper articles, screenshots of social media and so on. 


\section{International Academic Conference on Teaching, Learning and Education}

MILAN, ITALY

The evaluation found improvements in students' ability to identify disinformation, propaganda, facts, opinions, and hate speech after teachers incorporated what they had learn from the workshops in their classes. Students who received training also demonstrated higher levels of news media knowledge, better analysis skills of the political extremist propaganda, and healthier media consumption habits compared to their peers in a controlled survey. DEMOKLEOS students found workshops that integrated deconstruction of on-line extremism lessons more interesting and memorable than the students who did not take training integrated with Media Propaganda Education.

We hope our experiences may be valuable to other educational practitioners interested in exploring Media literacy education as a cross-disciplinary pedagogy to promote critical thinking about contemporary Media Political Propaganda and inspire additional inquiry through research. Additionally, networking between school and academic teachers improves the knowledge about the effects and the reception of online propaganda containing political extremism. There is no "one-fits-all solution" to an effective implementation of Media Political Education. Thus, lessons learned from DEMOKLEOS have to be seen as recommendations which need to be implemented in specific institutional and discursive contexts, and which aim at fostering a critical discourse between teachers, heads of schools, policy makers, civil society stake- holders and (scientific) experts in the field.

However, various challenges remain, limiting the impact and sustainability of an educational project as Erasmus+ KA2 DEMOKLEOS, "Rethinking Democratic Awareness and Collective Responsibility for a Whole School Approach". These challenges lie in the broader social and political contexts which shape educational policies, but are also linked to legal frameworks of the national governments. Obviously, political action and networking are required on various levels.

Teachers and schools on the frontline of the battle against the "Politics of fear" need to be supported and encouraged. They deserve respect and backing for the sustainability of democracy and the values that can lead to a better society for all citizens.

\section{Acknowledgment}

This paper is an output of the Erasmus +KA2 project, DEMOKLEOS, "Rethinking Democratic Awareness and Collective Responsibility for a Whole School Approach", funded by the European Commission (2015-2018), Cooperation for Innovation and the Exchange of Good Practices, Agreement No: 2015-1-EL01-KA201-013930

https://sites.google.com/site/edemokleos/ 


\section{Teaching, Learning and Education}

\section{References:}

[1] Aalberg, Toril, and Claes H. de Vreese., (2017). "Introduction: Comprehending Populist Political Communication." In Populist Political Communication in Europe, edited by Toril Aalberg, Frank Esser, Carsten Reinemann, Jesper Strömbäck and Claes H. de Vreese, pp. 311. London: Routledge.

[2] Altheide D.,

(2002). Creating fear: News and the construction of crisis. Hawthorne, NY, Aldine de Gruyter (2006). «Terrorism and the Politics of Fear", Cultural Studies Critical Methodologies, 6 (4), pp. 415-439.

[3] Anti-Defamation League (ADL), Computerized Networks of Hate: An ADL Fact Finding Report (New York: ADL, 1985). Available at https://archive.org/details/ComputerizedNetworksOfHate (accessed 27 June 2019).

[4] Arendt, H. (2011). Elemente und Ursprünge totaler Herrschaft: Antisemitismus, Imperialismus, totale Herrschaft. München: Piper. 14th ed.

15] Björgo, T. and Witte, R., (1993). “'Introduction'”. In Racist Violence in Europe, Edited by: Björgo, T. and Witte, R. 1-17. New York: St Martin's Press. [Google Scholar].

[6] Borg, J. \& Lauri, M. A. (2011). "A comparative study of EU documents on media literacy “, Media Education Research Journal, vol. 2(1), pp. 30-42

[7] Cummings, H., (1939). Teaching propaganda analysis: Clayton High School methods rank high among those of 400 schools. The Clearing House, 13(7), pp. 394-398.

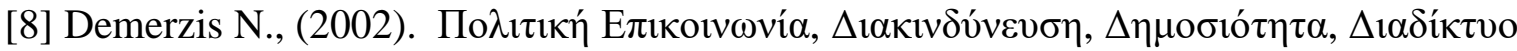
(Political Communication, Risk, Publicity, Internet), Athens: Papazisis.

[9] Edson, C. T., Lim, Z.W., \& Ling, R., (2018). Defining “fake news". Digital Journalism, vol 6(2), pp. 137-153.

[10] Ellenius, A., \& European Science Foundation, (1998). Iconography, propaganda, and legitimation. New York: Oxford University Press

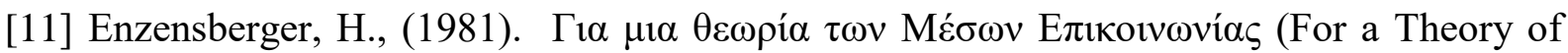
Media of Communication), Athens: Epikouros.

[12] European Association for Viewers Interest, (2011). Testing and Refining Criteria to Assess Media Literacy Levels in Europe, Final Report. Available at:

http://www.umic.pt/images/stories/publicacoes4/final-report-ML-study-2011_en.pdf (accessed 9 July 2018).

[13] European Commission/EACEA/Eurydice., (2016). Promoting citizenship and the common values of freedom, tolerance and non-discrimination through education: Overview of education 


\section{Teaching, Learning and Education}

policy developments in Europe following the Paris Declaration of 17 March 2015. Publications Office of the European Union. Luxembourg. Available at:

https://eurydice.org.pl/wp-content/uploads/2016/03/Leaflet_Paris_Declaration.pdf (accessed 12 September 2016).

[14] Giroux, H. A., (2003). The abandoned generation: Democracy beyond the culture of fear, New York, Palgrave Macmillan.

[15] Hacohen, C., (2012). 'The norm is a flux of change: Teachers' experiences in international schools", Educational Psychology in Practice, vol pp. 28 (2), 113-26.

[16] Hansen, T. D., (2001). Teaching as a moral activity. Handbook of research on teaching. Ur. Richardson, V. AERA. Washington, pp. 826-857.

[17] Harsin J., (2015), "Regimes of posttruth, postpolitics, and attention economies", Communication, Culture and Critique, vol.8(2), pp. 327-33.

[18] Hobbs, R., \& McGee, S., (2014). "Teaching about propaganda: an examination of the historical roots of media literacy", Journal of Media Literacy Education, vol. 6(2), pp. 56-71.

[19] Hogg, M.A., Kruglanski, A., van den Bos, K., (2013). "Uncertainty and the roots of extremism “, Journal of Social Issues, vol. 69, pp. 407-418.

[20] Jowett, G. and O'Donnell, V., (2015). Propaganda and Persuasion, 6th ed., London: Sage.

[21] Keyes, K., (2004). The Post-Truth Era: Dishonesty and Deception in Contemporary Life, New York: St. Martin's Press.

[22] Lasswell, H. D. (1927). "The theory of political propaganda", American Political Science Review, vol. 21(3), pp. 627-631.

[23] Norris, P., (2003). Young people \& political activism: From the politics of loyalties to the politics of choice? (Report for the Council of Europe Symposium: Young People and Democratic Institutions: From Disillusionment to Participation, Strasbourg, November 27-28, 2003). http://www.hks.harvard.edu/fs/pnorris/Acrobat/COE\%20Young\%20People\%20and\%20Politi cal\%20Activism.pdf

(accessed 10 March 2018).

[24] Peterson, A., (2016). "The institutionalization process of a Neo-Nazi movement party", in L. Bosi, M. Giugni and K. Uba (eds), The Consequences of Social Movements, Cambridge: Cambridge University Press, pp. 314-37.

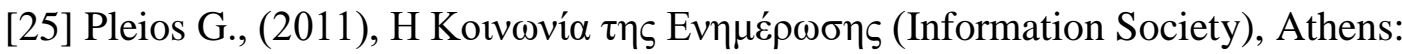

Kastaniotis.

[26] Snow, N. and Taylor, P., (eds) (2009), Routledge Handbook of Public Diplomacy, London: Routledge. 


\section{International Academic Conference on}

\section{Teaching, Learning and Education}

[27] Spiliotopoulou C.,

(Book style - Author, year. Title (in italics). Publisher, location of publisher.)

[1] Cichocki, A. and Unbehaven, R., (1993). Neural Networks for Optimization and Signal Processing, 1st ed. Chichester, U.K.: Wiley.

[2] Chen, W. K. (1993). Linear Networks and Systems, Belmont, CA: Wadsworth, pp. 123135.

(Journal - Author, year. Paper title. Journal name (in italics), volume and issue numbers, inclusive pages.)

[3] Chen, S., Mulgrew, B. and Granta, P. M. (1993). "A clustering technique for digital communications channel equalization using radial basis function networks," IEEE Trans. on Neural Networks, vol. 4, pp. 570-578.

[4] Hill, R. M. (1997). The single-vendor single-buyer integrated production-inventory model with a generalized policy, European Journal of Operational Research, vol. 97, pp. 493-499.

\section{(Online Sources style)}

[5] Vidmar, R. J. (August 1992). On the use of atmospheric plasmas as electromagnetic reflectors. IEEE Trans. Plasma Sci. [Online]. 21(3). pp. 876-880. Available: http://www.halcyon.com/pub/journals/21ps03-vidmar

(Conference paper or contributed volume - Author, year, paper title. Proceedings title (in italics). City, country, inclusive pages.)

[6] Beck, K. and Ralph, J. (1994). Patterns Generates Architectures. Proceedings of European Conference of Object-Oriented Programming. Bologna, Italy, pp. 139-149. 